- Original Article

\title{
Effect of gabapentin premedication on preoperative anxiety and postoperative pain
}

\author{
L Pathak ${ }^{1}$, A Chaturvedi ${ }^{2}$ \\ Department of Anesthesiology, \\ ${ }^{1}$ UCMS, Bhairahawa, Nepal and ${ }^{2} \mathrm{NS}$ Centre, AIIMS, India
}

\begin{abstract}
Background: In addition to chronic pain and anxiety disorders, few studies have found promising role of gabapentin in relieving acute postoperative pain as well as acute anxiety too. Objectives: To evaluate the effect of gabapentin premedication on preoperative anxiety and postoperative pain in patients undergoing elective open cholecystectomy. Methods: A prospective, randomized, double blind and placebo controlled study. Eighty adult patients of ASA I and II were divided into 2 groups of 40 each. Patients in group 1 and group 2 received capsules Gabapentin (1200mg) or identical placebo capsules 2 hours prior to surgery respectively. Preoperative anxiety and 12 hours postoperative pain was assessed using Anxiety and Pain VAS score respectively along with the observation of side effects. Postoperatively, intravenous pethidine $0.5 \mathrm{mg} / \mathrm{kg}$ was given when pain VAS $\geq 40 \mathrm{~mm}$ and time to first pethidine injection and total pethidine consumption in 12 hours was recorded. Results: Anxiety VAS scores after one hour of drug intake (35.75 \pm 20.11 versus $46.63 \pm 12.73$ ) and just before induction of anaesthesia (45.75 \pm 30.27 versus $68.13 \pm 29.84$ ) along with postoperative Pain VAS scores were significantly lower in gabapentin group. Time to the first pethidine demand was significantly longer (145.34 $\pm 194.54 \mathrm{~min}$ versus $26.30 \pm 51.02 \mathrm{~min})$ and cumulative pethidine consumption throughout study period was also significantly lower (35.91 \pm 16.61 versus $57.84 \pm 20.72 \mathrm{mg}$ ) in gabapentin group. Conclusions: $1200 \mathrm{mg}$ gabapentin premedication in open cholecystectomy patients significantly reduced preoperative anxiety, postoperative pain and total pethidine consumption with negligible side effects.
\end{abstract}

Key words: Gabapentin, acute anxiety, acute postoperative pain

\section{Introduction}

Acute preoperative anxiety and postoperative pain are interrelated. Successful treatment of both directly affect perioperative course and improve the final outcome of patients. Acute anxiety and pain exerts significant haemodynamic stress response resulting in increased cardiac output and myocardial oxygen consumption. In addition, it also do psychological harm to the patient.

Multimodal approaches are being used to manage perioperative pain using various drugs like NSAIDs,

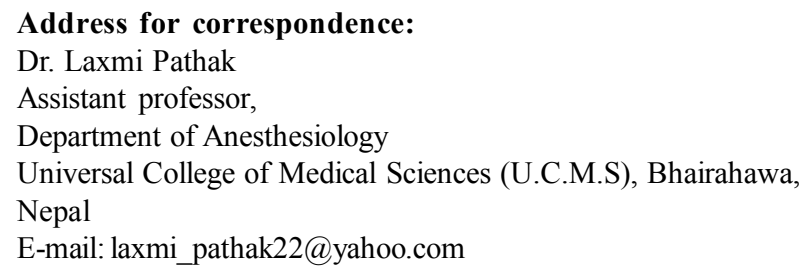

Paracetamol, Ketamine, antidepressants and anticonvulsants with opioid to reduce upload doses and its side effects. Gabapentin is one of them. ${ }^{1-9}$ It has antihyperalgesic, antinociceptive and also anxiolytic properties. Unlike benzodiazepines, it has less side effects and more safety of margin. ${ }^{10}$ It is being used in the management of chronic anxiety disorders but its role in relieving acute anxiety is limited. So, this study was carried out to evaluate the efficacy and safety of Gabapentin premedication on preoperative anxiety and acute postoperative pain in elective open cholecystectomy. 


\section{Methods}

After taking approval of institutional ethics committee and written informed consent from patients, this open prospective randomized placebo controlled double blind study was carried out in 80 adult patients (18-60yrs) of ASA physical status Grade I and II of both genders undergoing elective open cholecystectomy under general anaesthesia.

Patients with body weight more than $20 \%$ of ideal body weight; history of chronic pain conditions, drug or alcohol abuse, gabapentin hypersensitivity; administration of analgesics within 24 hours of scheduled surgery; cardio-respiratory problems, renal and hepatic diseases; and neuromuscular or psychiatric disorder were excluded from the study.

During pre-anesthetic evaluation patients were explained about $100 \mathrm{~mm}$ visual analogue scale (VAS) for pain and anxiety: a Pain VAS $(0=$ no pain to $100=$ worst imaginable pain) and an Anxiety VAS $(0=$ no anxiety to $100=$ worst imaginable anxiety).

Patients were divided into 2 groups of 40 each and assigned randomly in a double blind fashion via random number table to receive either capsule Gabapentin 1200 mg (Group 1 or Gabapentin group) or an identical looking placebo (Group 2 or control group) orally 2 hours prior to surgery ( $\mathrm{n}=40$ per group). No sedative premedication other than gabapentin was used. Personnel involved in the patient management and data collection was unaware of the group assignment.

In the operation room, baseline vitals \{heart rate, noninvasive blood pressure and oxygen saturation $\left(\mathrm{SpO}_{2}\right)$ \} were recorded. Anxiety level was assessed at the time of drug intake (Anxiety VAS-1), one hour after the drug intake (Anxiety VAS-2) and just before induction of anesthesia (Anxiety VAS-3). Anaesthesia was induced with intravenous propofol $2 \mathrm{mg} / \mathrm{kg}$ followed by vecuronium $0.08 \mathrm{mg} / \mathrm{kg}$ to facilitate orotracheal intubation. Intravenous pethidine $1 \mathrm{mg} / \mathrm{kg}$ bolus was given for intraoperative analgesia. Anaesthesia was maintained with oxygen, isoflurane 2 volume $\%$ and intermittent $1 \mathrm{mg}$ boluses of Vecuronium. Isoflurane was discontinued at the beginning of skin closure. At the end of surgery and after initiation of spontaneous respiration, reversal of neuromusmular blockade was done with intravenous Neostigmine $0.05 \mathrm{mg} / \mathrm{kg}$ and Glycopyrrolate $0.01 \mathrm{mg} / \mathrm{kg}$. After patient started obeying commands, trachea was extubated. Then, patients were shifted to post anesthesia care unit (PACU) to observe for 6 hours.

Intraoperative haemodynamic parameters were recorded at 15 minutes interval with total blood loss, length of anaesthesia, length of surgery and time to tracheal extubation. Time from induction of anaesthesia up to switching off isoflurane (at the start of skin closure) was considered as the length of anaesthesia $\{\mathrm{L}-$ Anaesthesia (minute) $\}$. Length of surgery was defined as the time interval between skin incision to the end of skin closure $\{$ L-Surgery (minute) $\}$. Time interval between switching off the isoflurane and tracheal extubation was considered as the time to tracheal extubation $\{$ T-Extubation (minute) $\}$.

In PACU, Pain VAS was measured during rest and on movement every 15 minutes for the first hour and then hourly for the next 5 hours. Then, patient was transferred to the ward where pain VAS assessment was done every 2 hourly for 6 hours. Intravenous pethidine $0.5 \mathrm{mg} / \mathrm{kg}$ was used as postoperative analgesic when Pain VAS was $\geq 40 \mathrm{~mm}$ (not repeated within half hour) and total pethidine consumption in 12 hours was recorded. Time interval between admission to PACU and the patient's first requirement for analgesic (i.e. time to first analgesic demand) was also noted. Along with the pain VAS, heart rate, blood pressure, $\mathrm{SpO}_{2}$ and side effects likenausea, vomiting, retching, dizziness, vertigo, somnolence, tremor, visual disturbance, lightheadedness, headache, sedation, ataxia and respiratory depression (Respiratory rate $<8 / \mathrm{min}$ and $\mathrm{SpO} 2<90 \%$ without oxygen supplement) were also observed postoperatively.

Side effects observed were treated whenever indicated like respiratory depression or $\mathrm{SpO}_{2}<90 \%$ was treated with oxygen supplementation, $\geq 2$ episodes of vomiting was treated with Ondansetron $4 \mathrm{mg}$ intravenously. The Ramsay sedation scale was used to assess sedation perioperatively.

Statistics: Morphometric and demographic characteristics of patients, clinical variables, anxiety and pain scores along with cumulative pethidine consumption over 12 hours in both gabapentin and control groups were compared with student's t-test. Chi square test was used to compare the qualitative data. Results are expressed as mean \pm SD. P $<0.05$ was considered statistically significant. 


\section{Results}

The two groups were comparable with respect to demographic characteristics (age, weight and sex), length of anaesthesia and surgery, time to tracheal extubation and intraoperative blood loss (Table 1).

Table 1: Patient characteristics and intra-operative data

\begin{tabular}{|c|c|c|c|c|}
\hline & $\begin{array}{c}\text { Group } 1 \\
(n=40)\end{array}$ & $\begin{array}{c}\text { Group2 } \\
(n=40)\end{array}$ & val \\
\hline \multicolumn{2}{|c|}{ Age $(y$} & $41.48 \pm 11.58$ & $37.40 \pm 11.13$ & 113 \\
\hline \multicolumn{2}{|c|}{$\mathrm{Wt}(\mathrm{kg})$} & $51.03 \pm 7.97$ & $50.15 \pm 8.61$ & \\
\hline \multirow[t]{2}{*}{ Sex } & $\mathrm{M}$ & 7 & & \multirow{2}{*}{0.518} \\
\hline & $\mathrm{F}$ & 33 & 36 & \\
\hline \multicolumn{2}{|c|}{$\begin{array}{l}\text { L-Anaesthesia } \\
\text { (min) }\end{array}$} & 61.10 & 5.60 & 0.882 \\
\hline \multicolumn{2}{|c|}{\begin{tabular}{|l} 
L- Surgery \\
(min)
\end{tabular}} & $56.68 \pm 17.22$ & $56.75 \pm$ & 0 \\
\hline \multicolumn{2}{|c|}{$\begin{array}{l}\text { T- Extubation } \\
\text { (min) }\end{array}$} & 4.38 & 4.0 & 213 \\
\hline \multicolumn{2}{|c|}{ B- Loss (ml) } & $34 \pm 15.53$ & $37.25 \pm 28.4$ & 0.528 \\
\hline
\end{tabular}

All the values are in mean $( \pm)$ SD except sex.

Table 2: Preoperative Anxiety VAS scores

\begin{tabular}{|l|c|c|c|}
\hline & $\begin{array}{c}\text { Group 1 } \\
(\mathbf{n = 4 0 )}\end{array}$ & $\begin{array}{c}\text { Group 2 } \\
(\mathbf{n = 4 0 )}\end{array}$ & P value \\
\hline Anxiety VAS 1 & $45.38 \pm 20.83$ & $43.75 \pm 20.12$ & 0.724 \\
\hline Anxiety VAS 2 & $35.75 \pm 20.11$ & $46.63 \pm 12.73$ & 0.005 \\
\hline Anxiety VAS 3 & $45.75 \pm 30.27$ & $68.13 \pm 29.84$ & 0.001 \\
\hline $\begin{array}{l}\text { Mean Anxiety } \\
\text { VAS Score }\end{array}$ & $42 \pm 19.72$ & $52 \pm 16.28$ & 0.011 \\
\hline
\end{tabular}

The values are in mean $( \pm)$ SD.

Table 3: Frequency of analgesic given within 12 hrs

\begin{tabular}{|c|c|c|c|c|c|}
\hline & \multicolumn{4}{|c|}{ Frequency (f } & P value \\
\hline & 0 & 1 & 2 & 3 & \\
\hline Group 1 (n) & 11 & 20 & 7 & 2 & 0.000 \\
\hline Group 2 (n) & 0 & 4 & 21 & 15 & \\
\hline
\end{tabular}

The values are in mean $( \pm)$ SD.

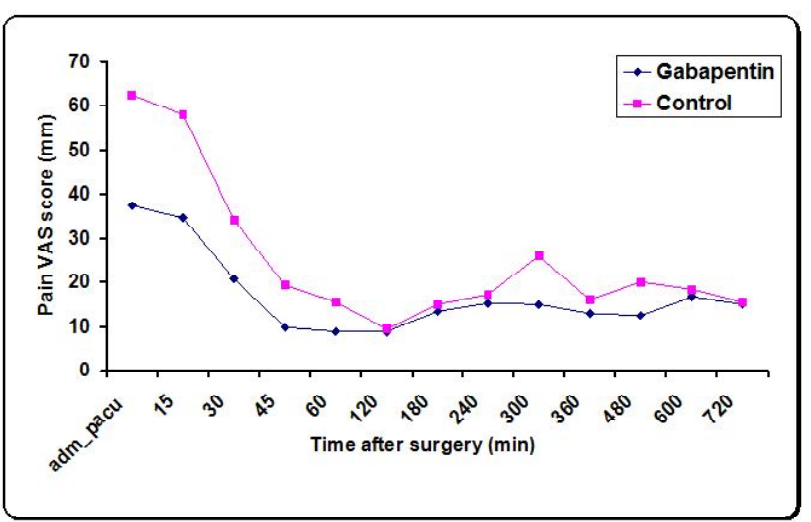

Figure 1: Pain VAS graph at rest

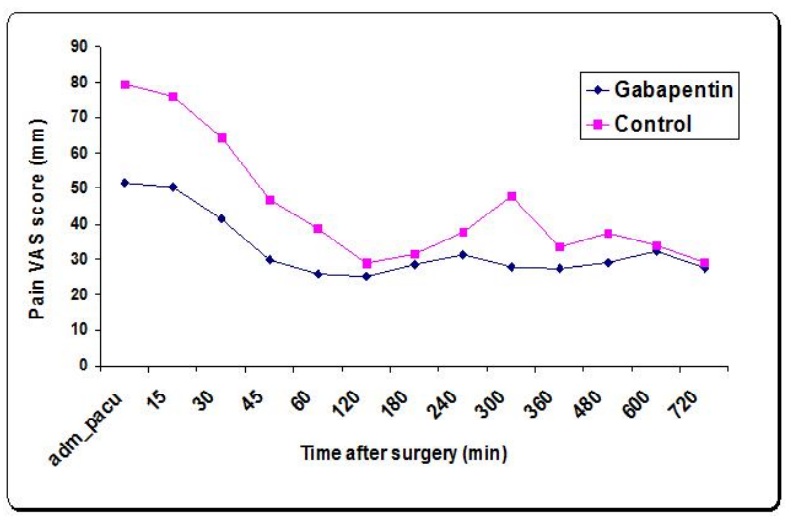

Figure 2: Pain VAS graph on movement

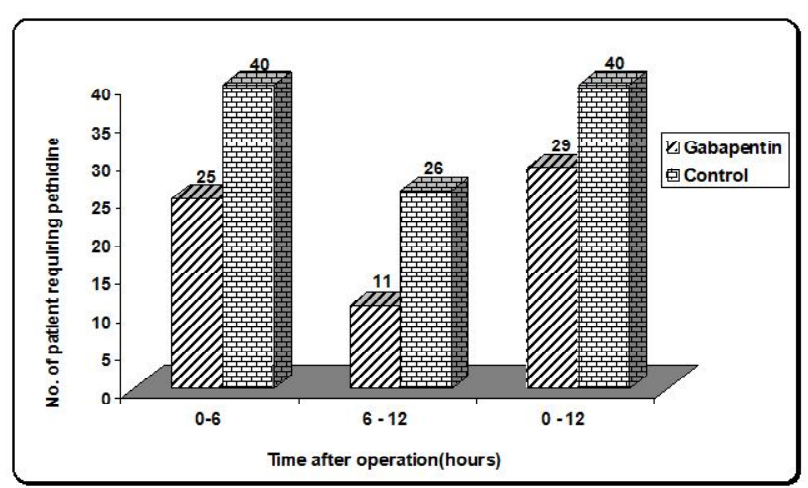

Figure 3: No. of patients requiring pethidine

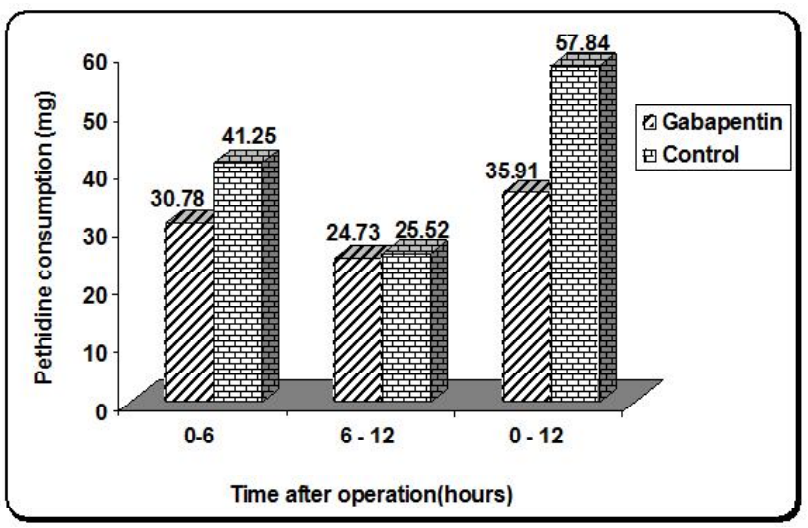

Figure 4: Pethidine consumption

Preoperative VAS anxiety scores after one hour of drug intake and just before induction were significantly lower in gabapentin group than in control group (Table 2). Postoperative VAS pain scores throughout the study period were lower in gabapentin group than in the control group both at rest and on movement (Figure1, 2). However, the decrease in pain VAS score at rest and on movement in gabapentin group was more significant during the first postoperative hour (the $\mathrm{P}$ value $<0.05$ ). 
Time to the first postoperative analgesic demand was significantly longer in gabapentin group (145.34 min) than in control group $(26.30 \mathrm{~min})$ with the $\mathrm{P}$ value of 0.000 . All 40 patients received intravenous pethidine in the control group whereas only 29 patients demand pethidine in the gabapentin group and 11 patients did not receive analgesic at all (Fig 3).

The frequency of analgesic demand during the study period was also significantly higher in control group than in gabapentin group with the $\mathrm{P}$ value of 0.000 . Most patients $(\mathrm{n}=36,90 \%)$ required multiple injections (2-3) in control group while most patients in gabapentin group $(\mathrm{n}=31,78 \%)$ required nil or 1 injection only (Table 3).

Total pethidine consumption in the first postoperative 6 hours and the cumulative pethidine consumption within 12 postoperative hours were significantly lower in gabapentin group than in control group $(30.78 \pm 11.17$ versus $41.25 \pm 15.42 \mathrm{mg}$ with $\mathrm{P}$ value of 0.005$)$ and $(35.91 \pm 16.61$ versus $57.84 \pm$ $20.72 \mathrm{mg}$ with the $\mathrm{P}$ value of 0.000 ) respectively (Figure 4).

Side effects were also lower in gabapentin group though not statistically significant. Five patients experienced nausea in control group whereas only 1 in gabapentin group. Vomiting, headache and dizziness, each was present in only one patient in control group and was treated. Other side-effects like vertigo, retching, blurred vision and respiratory depression were not observed in either group. All the patients were conscious and cooperative with Ramsay sedation score of 2 or less in both the group throughout the study period.

\section{Discussion}

The main observation of this study was that by simply giving a single $1200 \mathrm{mg}$ dose of Gabapentin as premedicant not only significantly reduced postoperative pain but also reduced preoperative anxiety level in patients undergoing elective open cholecystectomy and is without any significant adverse effects.

Gabapentin has been used for the treatment of convulsion, chronic pain and anxiety disorders for a long time. Its potential use to treat acute pain was initially evaluated by Werner et $\mathrm{al}^{11}$ in human volunteers. Later on, many studies ${ }^{1-9}$ found that gabapentin decreases postoperative pain and total opioid consumption using various doses and dosage schedule. Dierking et al ${ }^{1}$ used high and multiple doses of gabapentin total up to
$3000 \mathrm{mg}$, administered before and during the first 24 hour after abdominal hysterectomy and observed reduction in postoperative morphine consumption. Several studies with single $1200 \mathrm{mg}$ gabapentin used preemptively in various surgery like radical mastectomy $^{4}$, spinal surgery ${ }^{8}$, vaginal hysterectomy ${ }^{6}$, thyroid surgery ${ }^{10}$ and arthroscopic knee surgery ${ }^{12}$ have shown decrease postoperative pain and total opioid consumption with no or tolerable side effects. Preemptive administration of gabapentin approximately 2 hours before surgery appears rational in order to attain maximal plasma concentrations at the time of surgical stimuli. It crosses blood-brain-barrier rapidly and consequently its concentration in brain tissue, where it exhibits its effect, is nearly as high as in blood. ${ }^{13}$

We also used gabapentin preemptively 2 hours prior to induction and found it effective as an adjuvant analgesic especially in the immediate postoperative period. This was evident by decrease in postoperative pain VAS scores both during rest and movement, reduced frequency of analgesic demand, significant prolonged time to first postoperative analgesic demand when compared to placebo (146 minutes versus 26 minutes) and reduction in total pethidine consumption up to $38 \%$ throughout the study period.

Gabapentin also possess anxiolytic property with no effect on memory. De-Paris et al ${ }^{14}$ described reduced anxiety after intraperitoneal administration of gabapentin and diazepam in rats with unaffected memory only in gabapentin group. In 2005, Sethi A et al also did not found any adverse effect of gabapentin on memory suggesting its potential advantage over the existing anxiolytics, which show amnesia at doses used for the treatment of anxiety disorders. ${ }^{10}$ In psychiatric patients with co-morbid anxiety and social phobia ${ }^{15}$, an adjunctive gabapentin trial also showed improved sleep and reduced anxiety. One study has demonstrated that its derivative pregabalin was also effective in social phobia and generalized anxiety disorder. ${ }^{16}$ Not only in chronic anxiety state, gabapentin has also been found effective in treating acute anxiety associated with panic disorders. ${ }^{15,17,18}$ De-Paris F et al in 2003 again investigated to see the effects of gabapentin $400 \mathrm{mg}$ and $800 \mathrm{mg}$ on anxiety induced by simulated public speaking resembling preoperative anxiety state and found that gabapentin attenuated the anxiety of subjects that had a decrease in Visual Analogue Mood Scale and Profile of Mood State scores. ${ }^{19}$ 
Our study also showed significant reduction of preoperative anxiety VAS scores 1 hour after drug intake and just before induction of anaesthesia. Reducing preoperative anxiety with gabapentin may have also contributed in reducing postoperative pain and total analgesic consumption because there is a possible association between preoperative anxiety and postoperative pain..$^{20}$ Literature on acute anxiety relief by preemptive gabapentin use is very limited. Subsequent studies would be valuable to confirm the result of this study.

Studies performed in chronic pain patients on longterm gabapentin therapy have demonstrated its adverse effects like dizziness, somnolence, confusion, headache, nausea, ataxia and weight gain..$^{21,22}$ But, our findings are consistent with the findings in many single dose studies related to postoperative pain where no significant side effects like vomiting, retching, blurred vision, dizziness, headache and respiratory depression were observed. Further powered clinical investigations should define the appropriate dosing of gabapentin and occurrence of adverse effects.

\section{Conclusion}

Our findings suggest that a single $1200 \mathrm{mg}$ dose of gabapentin should be considered as a potential and safe premedicant drug which reduces acute preoperative anxiety, postoperative pain and total opioid requirement without any significant side effects.

\section{Acknowledgement}

I would like to acknowledge Dr. BP Sah, Dr. BP Das, Dr. CS Agrawal, Dr. SN Singh and Dr. DD Baral for their support in carrying out this study.

\section{References}

1. Dierking G, Duedahl TH, Rasmussen ML, Fomsgaard JS, Moiniche S, Romsing J et al. Effects of gabapentin on postoperative morphine consumption and pain after abdominal hysterectomy. Acta Anaesthesiol scand 2004; 48 (3):322-7.

2. Dirks J, Fredensborg BB, Christensen D, Fomsgaard JS, Flyger H, Dahl JB. A randomized study of effects of single dose Gabapentin verses placebo on postoperative pain and morphine consumption after mastectomy. Anaesthesiology 2002; 97:560-4.

3. Alprarslan T, Beyhan K, Dilek M, Pinar U, Zafer
$\mathrm{P}$, Mevlut T. The analgesic effects of gabapentin after total abdominal hysterectomy. Anesth Analg 2004; 98:1370-3

4. Rorarius MG, Mennander S, Suominen P, Rintala S, Puura A, Pirhonen R et al. Gabapentin for the prevention of postoperative pain after vaginal hysterectomy. Pain 2004; 110(1-2):175-81.

5. Pandey Ck, Priye S, Singh S, Singh U, Singh RB, Singh PK. Preemptive use of Gabapentin significantly decreases postoperative pain and rescue analgesic requirements in laproscopic cholecystectomy. Can. J Anaesth. 2004; 51(4):35863.

6. Turan A, Karamanhoglu B, Memis D, Hamamcioglu MK, Tukenmez B, Pamukcu Z et al. Analgesic effects of gabapentin after spinal surgery. Anesthesiology 2004; 100:935-8.

7. Radhakrishnan M, Bithal PK, Chaturvedi A. Effect of preemptive Gabapentin on postoperative Pain Relief and Morphine Consumption following Lumber Laminectomy and Discectomy. Neurosurg Anesthesiol 2005; 17:3.

8. Pandey CK, Singhal V, Kumar M, Lakra A, Ranjan $\mathrm{R}$, Raza $\mathrm{M}$ et al. Gabapentin provides effective postoperative analgesia whether administered preemptively or post-incision: Can J Anaesth. 2005; 52(8):827-31.

9. Hussain AM, Refri ARA, Katzarov MG, Dehrab NA, Batra YK, Rahim A et al. Preemptive gabapentin reduces postoperative pain and opioid demand following thyroid surgery. CAN J Anesth 2006; 53(3):268-273.

10. Sethi A, Das BP, Bajaj BK. The anxiolytic activity of gabapentin in Mice. B P Koirala Institute of Health Sciences, Dharan, Nepal. The Journal of Applied Research 2005; 5: 3.

11. Werner MU, Perkins FM, Holte K, Pedersen JL, Kehlet $\mathrm{H}$. Effects of gabapentin in acute inflammatory pain in humans. RegAnesth Pain Med 2001; 26:322-8.

12. Me'nigaux C, Adam F, Bruno G, Sessler DI, Chauvin Marcel. Preoperative Gabapentin reduces anxiety and improves early functional recovery from knee surgery. Anaesth Analg 2005; 100(5):1394-9.

13. Welty DF, Schielke GP, Vartanian MG, Taylor CP. 
Gabapentin anticonvulsant action in rats: disequilibri-um with peak drug concentrations in plasma and brain microdialysate. Epilepsy Res $1993 ; 16: 175-81$.

14. de - Paris F, Busnello JV, Vianna MRM, Salgueiro JB, Quevedo J, Izquierdo I et al. The anticonvulsant compound gabapentin possesses anxiolytic but not amnesic effects in rats. Behav Pharmacol 2000; 11(2):169-73.

15. Norton JW, Quarles E. Gabapentin and anxiety. Hosp Pharm 2001; 36:843-845.

16. Marco M, Stefano P, Cassano G B. The Role of Anticonvulsant Drugs in Anxiety Disorders: A Critical Review of the Evidence. Review Article. Journal of Clinical Psychopharmacology 2007; 27(3):263-272.

17. Grossman E, Nadler M, Sharabi Y, Thaler M, Shachar A, Shamiss A. Antianxiety treatment in patients with excessive Hypertension. Am J hypertens 2005; 18:1174 -7.
18. Pande AC, Pollack MH, Crockatt J,Greiner M, Chouinard G, Lydiard RB et al. Placebo-controlled study of gabapentin treatment of panic disorder. $\mathrm{J}$ Clin Psycho pharmacol 2000; 20:467-71.

19. de - Paris F, Sant' Anna MK, Vianna MR, Ivan I, Joao VB, Joao Quevedo et al. Effects of Gabapentin on Anxiety Induced by Simulated Public Speaking. Journal of Psychopharmacology 2003; 17(2):184188.

20. Kalkman CJ, Visser K, Moen J, Bonsel GJ, Grobbee DE, Moons KG. Preoperative prediction of severe postoperative pain. Pain 2003; 105(3):415-23.

21. McLean MJ, Morrell MJ, Willmore LJ, Privitera MD, Faught RE, Holmes GL et al. Safety and tolerability of gabapentin as adjunctive therapy in a large, multi-center study. Epilepsia 1999; 40:96572.

22. Mao J, Chen LL. Gabapentin in pain management. Anesth Analg 2000; 91:680-7. 